\title{
Cumulative BRCA mutation analysis in the Greek population confirms that homogenous ethnic background facilitates genetic testing
}

\author{
Alexandra Tsigginou ${ }^{1 *}$, Fotios Vlachopoulos ${ }^{1}$, Iordanis Arzimanoglou ${ }^{2}$, Flora Zagouri ${ }^{3}$ and Constantine Dimitrakakis ${ }^{1}$
}

\begin{abstract}
Screening for BRCA 1 and BRCA 2 mutations has long moved from the research lab to the clinic as a routine clinical genetic testing. BRCA molecular alteration pattern varies among ethnic groups which makes it already a less straightforward process to select the appropriate mutations for routine genetic testing on the basis of known clinical significance.

The present report comprises an in depth literature review of the so far reported BRCA 1 and BRCA 2 molecular alterations in Greek families. Our analysis of Greek cumulative BRCA 1 and 2 molecular data, produced by several independent groups, confirmed that six recurrent deleterious mutations account for almost $60 \%$ and $70 \%$ of all BRCA 1 and 2 and BRCA 1 mutations, respectively.

As a result, it makes more sense to perform BRCA mutation analysis in the clinic in two sequential steps, first conventional analysis for the six most prevalent pathogenic mutations and if none identified, a second step of New Generation Sequencing-based whole genome or whole exome sequencing would follow. Our suggested approach would enable more clinically meaningful, considerably easier and less expensive BRCA analysis in the Greek population which is considered homogenous.
\end{abstract}

Keywords: BRCA, Molecular alteration, Pathogenic mutation, Molecular genetic testing, Family/personal history, Inherited breast cancer, Greece

\section{Introduction}

Breast cancer is the most common malignancy among women in Greece involving $23 \%$ of all types of cancers [1]. According to World Health Organization $~ 87$ women in a 100.000 Greek population will develop breast cancer in their life time [2] with a relatively small proportion of it to be classified as hereditary. Multiple genes have been recognized to confer a risk of familial breast cancer, but in more than $70 \%$ of familial breast cancer cases the genetic factor remains unclear. In the remaining proportion, genetic testing can identify a pathogenic mutation of $B R C A 1$ or $B R C A 2$ in more than $25 \%$ of the affected families while other known genes namely TP53, PTEN, STK11, CHEK2, ATM may account for no more than $1 \%$ of the total familial breast

\footnotetext{
* Correspondence: atsigginou@outlook.com.gr

${ }^{1}$ Breast Unit of the 1st Department of Obstetrics and Gynecology, Athens University Medical School, Athens, Greece

Full list of author information is available at the end of the article
}

cancer $[2,3]$. The inheritance of a deleterious mutation in one of the two breast cancer susceptibility genes, $B R C A 1$ and 2 , is associated with a high lifetime risk of breast cancer, currently estimated at $65 \%$ (CI 44-78 \%) for $B R C A 1$ and $45 \%$ (CI:31-56 \%) for BRCA 2 [3]. Deleterious mutations in $B R C A$ genes also increase the lifetime risks of ovarian cancer and predispose to a range of other malignancies.

It is widely accepted that the distinct differences in cancer incidence and mortality observed among different ethnic groups may appear due to ethnic background dependent variant genetic component associated with the disease combined to other non-genetic, epidemiologic and life style connected risk factors. It is also documented that different mutations concerning specific predisposition gene(s), in our case $B R C A 1$ and $B R C A$ 2, may characterize different ethnic populations. Inherited gene alterations which persistently appear from generation to generation in specific ethnic groups can characterize those 
groups/populations and constitute what is known as founder effect, which apparently is due to a shared common ancestry [4]. According to the literature, the founder effect is the reduction in genetic variation or a gene mutation observed in high frequency in a specific population (add reference). Thus, it makes sense from the clinical point of view to retrospectively analyze cumulative $B R C A$ molecular data for $B R C A$ alterations confined to the Greek population, which is considered over $95 \%$ genetically homogeneous. Ultimately, this might help in developing a meaningful, comprehensive and cost-effective $B R C A$ diagnostic and prognostic tool to be offered to high-risk individuals or breast/ovarian cancer patients [5].

$B R C A 1$ and BRCA 2 genes normally produce tumor suppressor effect and it is commonly accepted that their germline mutations account for the majority of the identified and diagnosed familial and hereditary breast and ovarian cancers $[6,7]$. Breast cancer attributed to $B R C A$ 1 and $B R C A 2$ mutations tend to appear in younger age and exert a more aggressive phenotype $[8,9]$. Thus, genetic testing for predisposition to breast cancer before the spring of the disease and a more accurate molecular diagnosis are both essential in applying preventive measures to individuals at risk and, for women with cancer, patient stratification towards a more personalized medical treatment in the long run. In this context, genetic testing for $B R C A 1$ and BRCA 2 is recommended to breast cancer patients diagnosed before age of 50 , with bilateral breast cancer, and/or triple negative breast cancer, and/or history of ovarian cancer, and/or more than two first degree relatives with breast or ovarian cancer. Following a positive for mutation diagnosis, other affected and unaffected members of the family are screened for the specific mutation. Genetic testing should also be considered for women with distinct family history of breast and/or ovarian cancer where affected relatives cannot be screened $[10,11]$.

Despite the extensive $B R C A$ mutation screening of Greek patients and individuals at risk, there is not yet clear consensus as to what should be the most clinically appropriate $B R C A 1$ and $B R C A 2$ mutation panel for the Greek population. The present report constitutes a thorough analysis of the so far identified mutations in Greek families aimed to contribute to the real need to develop a standard and comprehensive $B R C A$ routine molecular test in the clinic.

\section{Methods}

We conducted a PubMed literature inquiry using as key words: Greek/breast cancer and genetics, which resulted in 99 studies. We then reviewed all papers reporting $B R C A 1$ and/or BRCA 2 molecular alterations and mutations in the Greek population and we found that only 14 of the total 99 studies were originally designed to solely include Greek families and patients. Cumulative Greek family data were collected and analyzed for the purpose to more precisely correlate, and perhaps associate specific $B R C A 1$ and 2 mutations to the Greek ethnic group.

\section{Results - review}

Currently, the exact proportion of breast cancer in Greece with documented genetic component cannot be accurately predicted, but it is believed to be comparable to the European rates. For the BRCA 1 and 2 genes in particular, which have long gained the attention of the global bio community, a large amount of Greek (resident within Greece or Greek-immigrant families) and GreekCypriot data have been produced. Cumulative Greek BRCA mutation data are shown in Table 1.

Historically, the first reported study in a Greek population by Konstantopoulou et al. (appeared in the literature in 2000) examined for BRCA 1 mutations 30 breast/ ovarian cancer patients with strong or moderate family history and premenopausal age at onset of the disease [12]. Three mutations previously described in non-Greek populations, (3741insA, 1623del5-TTAAA, 5382insC) and two novel ones (3099delT, 3277insG) were found. This finding was the first evidence that BRCA 1 mutations may account for as much as $20 \%$ of high-risk Greek families, incidence comparable to other European countries. This was also the first report correlating two novel mutations to the Greek population. Later, in 2003, Kroupis et al. reported a family affected with atypical medullary breast carcinoma carrying the 5382ins $C$ mutation and thus confirmed that this rather universal $B R C A 1$ mutation is detected in Greece too [13]. Later, the exact same mutation was found to be the most frequent mutation in Greek breast/ovarian cancer families [14]. Ladopoulou et al. examined eighty five patients with positive family history for BRCA 1 and $B R C A 2$ deleterious mutations and 14 were found to carry 6 mutations: the aforementioned $5382 \mathrm{ins} C$, the non-sense $R 1751 X$ and the $5586 G>A$ of $B R C A 1$, and frameshifts 2024del5, 3034del4, and 6631del5 of BRCA 2. Molecular alterations of yet unknown biological significance including some with higher than $1 \%$ frequency and thus potentially constituting polymorphisms were also reported.

Armaou et al. studied 95 patients of Northern Greece, for $B R C A 1$ molecular alterations. Four deleterious deletions in exons 20 and 24 were found in this study, one of which was reported to be novel. There were two carriers of that newly identified mutation; one developed breast cancer at 28 years, ovarian cancer at 31 and endometrioid cancer at 38 and the second carrier developed ovarian cancer at 52 and breast cancer at 53 years. Hence, this mutation is a strong candidate to be included in the Greek $B R C A 1$ mutation panel to diagnose women with high risk to develop early onset breast and ovarian cancer [15]. 
Table 1 BRCA 1 and BRCA 2 mutations found in a Greek population. (Mutations repeatedly found in multiple papers share the same font colors)

\begin{tabular}{|c|c|c|c|c|}
\hline \multirow[t]{2}{*}{ Author } & \multicolumn{2}{|l|}{ Pathogenic mutation } & \multirow[t]{2}{*}{ Sample/methods used } & \multirow[t]{2}{*}{ Results } \\
\hline & BRCA1 & BRCA2 & & \\
\hline \multirow[t]{3}{*}{ Konstantopoulou et al., 2000 [12] } & 3741 insA, 1623del5-TTAAA & & \multirow{2}{*}{$\begin{array}{l}30 \text { breast/ovarian cancer pts } \\
\text { with family history }\end{array}$} & \multirow{3}{*}{$\begin{array}{l}5 \text { mutations \& } 6 \\
\text { polymorphisms }\end{array}$} \\
\hline & \multirow{2}{*}{ 5382insC, 3099delT, 3277insG } & & & \\
\hline & & & PTT, direct sequencing & \\
\hline \multirow[t]{2}{*}{ Armakolas et al., 2002 [18] } & & \multirow[t]{2}{*}{ 2024del5 3058delA 6024del TA 4147del G } & $\begin{array}{l}55 \text { bc pts: } 27 \text { with family } \\
\text { history, } 28 \text { sporadic bc }\end{array}$ & \multirow[t]{2}{*}{4 different mutations in 5 pts } \\
\hline & & & SSCP, sequencing & \\
\hline \multirow[t]{2}{*}{ Ladopoulou et al. 2002 [14] } & \multirow[t]{2}{*}{ 5382insC non-sense R1751X 5586G > A } & \multirow[t]{2}{*}{ 2024del5 3034del4 6631del5 } & 85 pts with positive history & \multirow{2}{*}{$\begin{array}{l}\text { Mutations in } 14 \text { families } \\
(16.5 \%)\end{array}$} \\
\hline & & & PTT, SSCP, direct sequencing & \\
\hline Kroupis et al., 2003 [13] & 5382insC & & Study of one affected family, & \\
\hline \multirow[t]{2}{*}{ Belogianni et al., 2004 [16] } & \multirow[t]{2}{*}{$\begin{array}{l}\text { exon 20: } 5331 \mathrm{G}>\mathrm{A}, 5382 \mathrm{ins} \mathrm{C} \text {, entire exon } 20 \\
\text { deletion exon 23:5586 G>A }\end{array}$} & & $\begin{array}{l}25 \text { individuals of } 18 \mathrm{fms} / 12 \\
\text { high risk }\end{array}$ & \multirow[t]{2}{*}{$\begin{array}{l}5 \text { fms were positive for } \\
\text { mutation }\end{array}$} \\
\hline & & & dHPLC, MLPA, Long PCR & \\
\hline \multirow[t]{2}{*}{ Kataki et al., 2005 [19] } & \multirow{2}{*}{$\begin{array}{l}2306 \mathrm{~A}>\mathrm{T}, 4750 \mathrm{C}>\mathrm{A}, 5129 \mathrm{~A}>\mathrm{C}, 5627 \mathrm{G}>\mathrm{T} \text {, IVS8- } \\
19 \mathrm{delT}, 2196 \mathrm{G}>\mathrm{A}, 4793 \mathrm{~A}>\mathrm{G}, 4956 \mathrm{~A}>\mathrm{G} \\
4610 \mathrm{~T}>\mathrm{C}\end{array}$} & \multirow[t]{2}{*}{$\begin{array}{l}\text { 4147delG (2 pts), 3058delA, 6024delTA, } \\
\text { 2024del5, 385A > G, 360 T>G }\end{array}$} & $\begin{array}{l}94 \text { individuals with low or } \\
\text { moderate risk to be carriers }\end{array}$ & \multirow{2}{*}{$\begin{array}{l}\text { BRCA1: } 5 \text { unclassified variants } \\
\text { \& } 4 \text { polymorphisms BRCA 2: } 5 \\
\text { unclassified variants \& } 1 \\
\text { polymorphism }\end{array}$} \\
\hline & & & PTT, SSCP, sequencing & \\
\hline \multirow[t]{2}{*}{ Armaou et al., 2007 [15] } & \multirow{2}{*}{$\begin{array}{l}\text { exon 20:71146-75319del, 71618-74863del exon } \\
\text { 24:82651-87079del, 82651-87079del }\end{array}$} & & \multicolumn{2}{|c|}{95 pts with positive family history (one case of sporadic Ca) } \\
\hline & & & \multicolumn{2}{|l|}{ QMPSF, diagnostic PCR primers } \\
\hline Anagnostopoulos et al., 2008 [20] & $5331 G>A(G 1738 R)$ & & $\begin{array}{l}287 \text { breast/ovarian cancer famili } \\
\text { mutation/PCR sequencing }\end{array}$ & es Study specific for G1738R \\
\hline \multirow[t]{2}{*}{ Konstantopoulou et al., 2008 [21] } & \multirow[t]{2}{*}{ exon 20: 5382insC, 5331G > A (G1738R) } & \multirow[t]{2}{*}{ 3058delA 2024del5 } & 127 bc/ovarian cancer fms & \multirow{2}{*}{$\begin{array}{l}16 \mathrm{fms} \text { BRCA1 mut } \& 5 \mathrm{fms} \\
\text { BRCA2 mut }\end{array}$} \\
\hline & & & diagnostic $P C R$ primers, dHPLC & \\
\hline \multirow[t]{2}{*}{ Armaou et al. 2009 [23] } & \multirow[t]{2}{*}{$\begin{array}{l}\text { c.5266dupC, G1738R, and two deletions of exons } \\
20 \text { and } 24\end{array}$} & & $\begin{array}{l}987 \text { unselected pts examined } \\
\text { for specific mutations }\end{array}$ & \multirow[t]{2}{*}{$2.6 \%$ carriers } \\
\hline & & & diagnostic PCR primers, $P C R$ & \\
\hline \multirow[t]{2}{*}{ Koumpis et al. 2011 [22] } & $\begin{array}{l}\text { exon 20: } 5331 \mathrm{G} \text { > A, } 3.2 \text { kb deletion exon 11: } \\
\text { 3819delGTAAA }\end{array}$ & exon 11: 3782del10, 4512insT & $\begin{array}{l}127 \text { unselected sporadic bc } \\
\text { patients }\end{array}$ & $\begin{array}{l}6 \text { carriers found (no family } \\
\text { history) }\end{array}$ \\
\hline & & & $\begin{array}{l}\text { diagnostic PCR primers, } \mathrm{PCR} \text {, } \\
\mathrm{ABI}, \mathrm{PTT}\end{array}$ & \\
\hline Pertesi et al. 2011 [24] & exon 20:del D17S579 - D17S1299 (3.9 Mb) exon & & Study of affected families & \\
\hline & 24: del D17S951 , D17S1299 (2.9 Mb) & & diagnostic $\mathrm{PCR}$ primers (10 shor & t tandem repeat markers) \\
\hline Fostira et al., 2014 [25] & exon 11- (c.3178G > T) & & Case report of a carrier with nes & yative family history \\
\hline
\end{tabular}


Table 1 BRCA 1 and BRCA 2 mutations found in a Greek population. (Mutations repeatedly found in multiple papers share the same font colors) (Continued)

\begin{tabular}{|c|c|c|c|c|}
\hline Konstantopoulou et al. 2014 [26] & $\begin{array}{l}\text { exon 5: (300 T > G - C61G) exon 7: (449delG- } \\
\text { ter1 18)* exon 11: (1329insCT)*, (1623del5), } \\
(1624 \mathrm{~T}>\mathrm{G}-\mathrm{L} \text { L502X)*, (1806C > T - Q563X)*, } \\
\text { (2072del4), (2767insGGCA)*, (3082C > A - S988X)* } \\
\text {,(3297G > T - E1060X), (3494delTC), (3726C > T- } \\
\text { R1203X), (3741delA)*, (3819del5), (3874del4) exon } \\
\text { 12: (4286delTG)* exon 14: (4510delCTAinsTT) } \\
\text { exon20: (5331G > A - G1738R), (5370C > T - } \\
\text { R1751X), (5382insC), (g.71660_74860del3200) } \\
\text { exon 21: (5447delC) exon 22: (IVS22 + 5G >C) } \\
\text { exon 23: (5550C > T-Q1811X), (5586G > A), } \\
\text { (g.80280_91331del11052) exon24: (5611delC), } \\
\text { (g.82651_87079del4429_ins5) }\end{array}$ & $\begin{array}{l}\text { exon8- (886delGT) exon 11: (2567C > G - } \\
\text { S780X), (3036del4), (4643del4), (4997delA), } \\
\text { (5950delCT), (6718C > T - Q2164X), (6828delTT) } \\
\text { exon 17: (IVS16-2A > T), (8204G > A) exon 19: } \\
\text { (8592G > A - W2788X) exon 22: (9158delA) } \\
\text { exon23: (9218del32) exon 24: 9325insA exon } \\
\text { 25: 9604C > T - Q3126X) exon 27: (9976insT) }\end{array}$ & $\begin{array}{l}473 \text { breast/ovarian cancer } \\
\text { patients with family history } \\
\text { diagnostic PCR primers, direct } \\
\text { sequencing, MLPA }\end{array}$ & $\begin{array}{l}32 \% \text { mutation prevalence. } 44 \\
\text { mutations found (6 BRCA1 } \\
\text { recurrent/founder mutations } \\
\text { dominate the observed } \\
\text { spectrum-58.5\% of all } \\
\text { mutations found) }\end{array}$ \\
\hline
\end{tabular}

(pts patients, bc breast cancer, fms families, mut mutation)

PTT Protein truncation test

SCCP Single-Strand Conformation Polymorphism Analysis

dHPLC denaturing High Performance Liquid Chromatography

MLPA Multiplex Ligation - dependent PCR Amplification

QMPSF Quantitative Multiplex PCR of Short Fluorescent Fragments

$A B I$, TaqMan Copy Number Variation Assays

*. novel mutations (the time the study was published) (footnote), indication deleted on the last cell of the table 
In another study, limited in Greece and Cyprus, 18 affected families examined for BRCA 1 mutations and four different mutations were found in five families : Mutation 5382ins $C$ in exon 20, missense mutation 5331G $>A$ in exon 20 , single base substitution $\mathrm{G}>\mathrm{A}$ at nucleotide 5586 in exon 23 and a first reported deletion of the entire exon 20 [16]. Also, it is worth mentioning that these mutations were associated to early onset breast cancer (occurring in 29 to 50 years) with variable penetration. Ovarian cancer presented in only one patient and there were also cases of colorectal, larynx and lungs neoplasms within these families, a pattern that resembles to $\mathrm{Li}$ Fraumeni cancer syndrome. The deletion of the entire exon 20 was identified in one Greek family and in one Italian family generated from different DNA alterations. Two unaffected mutation carriers aged 39 and 55 were diagnosed, suggesting that calculating genetic risk based on $B R C A 1$ alone may in fact be less informative than we currently think [17].

In 2002, the first study with Greek BRCA 2 mutations in breast cancer patients was published [18]. Armakolas et al. examined five distinct breast cancer families, and found one carrying the known germline deleterious mutation (2024del5) and three other families carrying novel mutations (3058delA, 6024delTA, and 4147delG). It is noteworthy that breast cancer patients with tumors carrying these mutations exhibited more favorable clinical phenotype compared to stage matched sporadic cases, irrespective of histological type. Also, it was observed that in a Greek population, this more favorable phenotype was correlated to a cluster of novel mutations in exons 10 and 11 [18].

Following, Kataki et al. examined 94 individuals with low or moderate risk for BRCA 1 and 2 mutations based purely on family history [19]. Three novel $B R C A 1$ missense mutations, one novel $B R C A 1$ intronic deletion, three $B R C A 2$ truncating mutations, and one novel $B R C A$ 2 missense mutation were identified.

According to the results of Anagnostopoulos et al. study, which involved 11 Greek families residents of Greece, Australia and USA, one missense mutation at $5331 G>A$ of exon 20 , accounts for $3 \%$ and $12.3 \%$ of all breast/ovarian cancer families and all carriers of deleterious mutations, respectively [20]. These results coupled to genealogical history, point to $5331 G>A$ mutation as a likely Greek founder effect. Not surprisingly, our analysis confirmed that the most common pathogenic BRCA 1 mutation in the Greek population is the 5382ins $C$ located also in exon 20, widely known as the Jewish founder, which remains to be the most common $(10 \%$ of all $B R C A$ 1 mutations) alteration amongst Caucasians worldwide, and therefore, can be associated with the Caucasian race [21]. Alternatively, our analysis further supports the view that $5382 i n s C$ is not an ethnic-specific characteristic but rather a "universal" Caucasian mutation. Unlike 5382insC, evidence indicates that the $B R C A 2$ mutations subst $G>A$ 5586 in exon 23 for BRCA 1 and 2024del5 and 3058delA can be considered as Greek-specific mutations [21].

Koumpis et al. [22] examined unselected by family history, breast cancer patients and six mutations were found (four in BRCA 1 and two in BRCA 2) which account for $4.7 \%$ of the total and for $9.5 \%$ of cases diagnosed before age forty. This result that breast cancer incidence doubles before the age of forty adds to the current belief of strong genetic component of early breast cancer onset. Recently, we have also published a series of breast cancer in women aged 25 years and younger where, the percentage of BRCA mutations raised to $25 \%$ of cases in this very young age group. The overall incidence of BRCA mutations found in Koumpis study is twice that found by Armaou et al. who studied only four selected mutations in Greek women with breast cancer [23] but in line with results published by others having studied non Greek ethnic background women. Notably, Koumpis et al. reported that only one of the six mutation carriers reported family history of breast or ovarian cancer, which strongly favors the current belief that many carriers share no previous family history of the disease. Taken together, the above data clearly indicate both, that other than the aforementioned BRCA mutations play a role in inherited Greek breast cancer and that breast cancer susceptibility may involve other than the $B R C A$ genes, consistent with the results published by International breast and ovarian cancer genetic predisposition consortia (http://www.ncbi.nlm.nih.gov/pubmed/25581431 and http://www.ncbi.nlm.nih.gov/pubmed/25452441.

Before us, Koumpis et al. supported the view that mutation $5331 G>A$ of exon 20 is likely to be founder effect in the Greek population [22]. In the same study, two novel $B R C A 1$ mutations, one $3.2 \mathrm{~kb}$ deletion in exon 20 and one in exon 11 (3819delGTAAA) and two BRCA 2 mutations in exon 11 (3782del10, 4512insT), were found. In addition, Pertesi et al. supported the view that the deletions of $3.9 \mathrm{Mb}$ of exon 20 and $2.9 \mathrm{Mb}$ of exon 24 may be Greek ethnic group-associated molecular events [24]. Furthermore, Fostira et all described the p.E1060X aggressive mutation in BRCA 1/exon 11 (c.3178G > T) that affected a young woman with no family history. The inheritance proved to originate from the paternal family that counted very few female members, fact which highlights the necessity of genetic testing even in cases with negative family history [25].

In a recent study, Konstantopoulou et al. [26] conducted a large survey screening 473 Greek breast/ovarian cancer families for BRCA 1 and BRCA 2 mutations. This study resulted in 28 different deleterious $B R C A 1$ mutations (9 novels, firstly identified) and 16 deleterious BRCA 2 mutations (7 novels) which apparently set the basis for the development of a diagnostic tool applicable to diagnose 
Greek familial breast/ovarian cancer. Interestingly, the great majority (up to $75 \%$ ) of the $B R C A 1$ families were positive for mutations located at the 3'end of the gene that include exons 20 to 24 . Alternatively, almost $60 \%$ of all Greek familial breast/ovarian cancer appear to be attributable to $B R C A 1$ mutations in the same region of the gene which, understandably, can streamline the whole mutation analysis process.

It has been now two decades of intense research targeted to BRCA 1 and 2 mutations covering a wide range of different ethnic populations. Most of the Greek studies cited here have predominantly focused on examining families with positive history in accordance with the current guidelines which recommend focusing BRCA genetic screening on unaffected members of affected families [27]. We now know that this biased approach towards breast cancer cases selected on a family history basis, has provided limited information as per the actual prevalence of BRCA 1 and 2 mutations in the Greek population and the actual penetrance of the disease in carriers. Moreover, increasing evidence indicates that a large fraction of families with a strong family history of breast cancer scores negative for $B R C A$ mutations which underlines the importance to always make a clear distinction between familial and inherited breast cancer, the former being a small subset of the latter. New genes, like $P A L B$ 2, are likely to emerge as the next breast cancer susceptibility gene(s) and their screening will gradually intensify, beyond any doubt [8]. However, this accumulative data confirms that in a homogenous ethnic population like Greek, common BRCA mutations can facilitate genetic testing.

\section{Conclusions}

Considerable effort has been made to detect and more accurately predict the BRCA 1 and 2 mutations with the highest frequency in the homogeneous Greek population. Our analysis of cumulative Greek $B R C A$ data clearly indicates that six specific mutations account for almost $60 \%$ of BRCA 1 and 2 mutations and $70 \%$ of BRCA 1 mutations. This observation strongly supports the view that a two-step BRCA analysis procedure might be more meaningful to be implemented in the Greek clinic. In other words, in clinical routine, every Greek woman referred for $B R C A$ screening can undergo screening for the six known mutation first and if the first step fails to diagnose a deleterious mutation, then a comprehensive New Generation Sequencing-based whole genome or whole exon analysis, as previously described by others (indicatively, http://www.ncbi.nlm.nih.gov/pubmed/25859162 and http://www.ncbi.nlm.nih.gov/pubmed/25896959) will follow. Only after $B R C A$ genetic testing of tens of thousands of Greek women will have been completed, we will be in a position to more accurately evaluate whether the suggested six mutation panel is the appropriate one or needs to be extended and/or changed for the purpose of the daily routine $B R C A$ testing in the clinic and whether one or more of these or new mutations may constitute a Greek founder effect.

\section{Competing interests}

The authors declare that they have no competing interests.

\section{Authors' contributions}

AT reviewed the literature and prepared the manuscript, FV has done the survey and contributed to manuscript preparation, IA consulted about the genetics background and critically reviewed the manuscript, FZ participated in data collection and CD designed and coordinated this study and also conferred to manuscript revision. All authors had reviewed and approved the above manuscript.

\section{Author details}

${ }^{1}$ Breast Unit of the 1st Department of Obstetrics and Gynecology, Athens University Medical School, Athens, Greece. ${ }^{2}$ Genomedica, S.A, Piraeus, Greece. ${ }^{3}$ Department of Clinical Therapeutics, Alexandra Hospital, Athens University Medical School, Athens, Greece.

Received: 23 January 2015 Accepted: 14 July 2015

Published online: 19 August 2015

\section{References}

1. Parkin DM, Bray F, Ferlay J, Pisani P: Global cancer statistics, 2002. CA Cancer J Clin. 2005;55(2):74-108.

2. Pharoah PD, Antoniou AC, Easton DF, Ponder BA: Polygenes, risk prediction, and targeted prevention of breast cancer. N Engl J Med. 2008;358(26):2796-2803.

3. Balmana J, Diez O, Rubio IT, Cardoso F: BRCA in breast cancer: ESMO Clinical Practice Guidelines. Ann Oncol. 2011;22: Suppl 6:vi31-4.

4. Ferla R, Calo V, Cascio S, Rinaldi G, Badalamenti G, Carreca I, Surmacz E, Colucci G, Bazan V, Russo A: Founder mutations in BRCA1 and BRCA2 genes. Ann Oncol. 2007;18 Suppl 6:vi93-98.

5. Liede A, Narod SA: Hereditary breast and ovarian cancer in Asia: genetic epidemiology of BRCA1 and BRCA2. Hum Mutat 2002;20(6):413-24.

6. Lynch HT, Snyder C, Casey MJ: Hereditary ovarian and breast cancer: what have we learned? Ann Oncol. 2013;24 Suppl 8:viii83-viii95.

7. Gauthier-Villars M, Gad S, Caux V, Pages S, Blandy C, Stoppa-Lyonnet D: Genetic testing for breast cancer predisposition. Surg Clin North Am 1999;79(5):1171-87, xxi.

8. Veronesi A, de Giacomi C, Magri MD, Lombardi D, Zanetti M, Scuderi C, Dolcetti R, Viel A, Crivellari D, Bidoli E et al: Familial breast cancer: characteristics and outcome of BRCA 1-2 positive and negative cases. BMC Cancer. 2005:5:70.

9. Fostira F, Tsitlaidou M, Papadimitriou C, Pertesi M, Timotheadou E, Stavropoulou AV, Glentis S, Bournakis E, Bobos M, Pectasides D et al: Prevalence of BRCA1 mutations among 403 women with triple-negative breast cancer: implications for genetic screening selection criteria: a Hellenic Cooperative Oncology Group Study. Breast Cancer Res Treat. 2012;134(1):353-62.

10. Berliner JL, Fay AM, Cummings SA, Burnett B, Tillmanns T: NSGC practice guideline: risk assessment and genetic counseling for hereditary breast and ovarian cancer. J Genet Couns. 2013;22(2):155-63.

11. Cardoso F, Costa A, Norton L, Senkus E, Aapro M, Andre F, Barrios CH, Bergh J, Biganzoli L, Blackwell KL et al: ESO-ESMO 2nd international consensus guidelines for advanced breast cancer (ABC2)dagger. Ann Oncol. 2014;25(10):1871-88.

12. Konstantopoulou I, Kroupis C, Ladopoulou A, Pantazidis A, Boumba D, Lianidou ES, Petersen MB, Florentin L, Chiotellis E, Nounesis G et al: BRCA1 mutation analysis in breast/ovarian cancer families from Greece. Hum Mutat. 2000;16(3):272-73.

13. Kroupis C, Lianidou E, Goutas N, Ladopoulou A, Konstantopoulou I, Pantazidis A, Yannoukakos D, Efstathiou E, Vourlidis N, Tsionou C: Atypical medullary breast carcinoma in a family carrying the 5382insC BRCA-1 mutation. Breast J. 2003;9(3):260-62. 
14. Ladopoulou A, Kroupis C, Konstantopoulou I, loannidou-Mouzaka L, Schofield AC, Pantazidis A, Armaou S, Tsiagas I, Lianidou E, Efstathiou E et al: Germ line BRCA1 \& BRCA2 mutations in Greek breast/ovarian cancer families: 5382insC is the most frequent mutation observed. Cancer Lett. 2002;185(1):61-70.

15. Armaou S, Konstantopoulou I, Anagnostopoulos T, Razis E, Boukovinas I, Xenidis N, Fountzilas G, Yannoukakos D: Novel genomic rearrangements in the BRCA1 gene detected in Greek breast/ovarian cancer patients. Eur J Cancer. 2007:43(2):443-53.

16. Belogianni I, Apessos A, Mihalatos M, Razi E, Labropoulos S, Petounis A, Gaki V, Keramopoulos A, Pandis N, Kyriacou K et al: Characterization of a novel large deletion and single point mutations in the BRCA1 gene in a Greek cohort of families with suspected hereditary breast cancer. BMC Cancer. 2004;4:61.

17. Montagna M, Dalla Palma M, Menin C, Agata S, De Nicolo A, Chieco-Bianchi L, D'Andrea E: Genomic rearrangements account for more than one-third of the BRCA1 mutations in northern Italian breast/ovarian cancer families. Hum Mol Genet. 2003;12(9):1055-61.

18. Armakolas A, Ladopoulou A, Konstantopoulou I, Pararas B, Gomatos IP Kataki A, Konstadoulakis MM, Stathopoulos GP, Markopoulos C, Leandros E et al: BRCA2 gene mutations in Greek patients with familial breast cancer. Hum Mutat. 2002;19(1):81-2.

19. Kataki A, Gomatos I, Pararas N, Armakolas A, Panousopoulos D, Karantzikos G, Voros D, Zografos G, Markopoulos C, Leandros E et al: Identification of germline BRCA1 and BRCA2 genetic alterations in Greek breast cancer moderate-risk and low-risk individuals-correlation with clinicopathological data. Clin Genet 2005, 67(4):322-329.

20. Anagnostopoulos T, Pertesi M, Konstantopoulou I, Armaou S, Kamakari S, Nasioulas G, Athanasiou A, Dobrovic A, Young MA, Goldgar D et al: G1738R is a BRCA1 founder mutation in Greek breast/ovarian cancer patients: evaluation of its pathogenicity and inferences on its genealogical history. Breast Cancer Res Treat. 2008;110(2):377-385.

21. Konstantopoulou I, Rampias T, Ladopoulou A, Koutsodontis G, Armaou S, Anagnostopoulos T, Nikolopoulos G, Kamakari S, Nounesis G, Stylianakis A et al: Greek BRCA1 and BRCA2 mutation spectrum: two BRCA1 mutations account for half the carriers found among high-risk breast/ovarian cancer patients. Breast Cancer Res Treat. 2008;107(3):431-441.

22. Koumpis C, Dimitrakakis C, Antsaklis A, Royer R, Zhang S, Narod SA, Kotsopoulos J: Prevalence of BRCA1 and BRCA2 mutations in unselected breast cancer patients from Greece. Hered Cancer Clin Pract. 2011;9:10.

23. Armaou S, Pertesi M, Fostira F, Thodi G, Athanasopoulos PS, Kamakari S, Athanasiou A, Gogas H, Yannoukakos D, Fountzilas G et al: Contribution of BRCA1 germ-line mutations to breast cancer in Greece: a hospital-based study of 987 unselected breast cancer cases. Br J Cancer. 2009;101(1):32-37.

24. Pertesi M, Konstantopoulou I, Yannoukakos D: Haplotype analysis of two recurrent genomic rearrangements in the BRCA1 gene suggests they are founder mutations for the Greek population. Clin Genet. 2011;80(4):375-382.

25. Fostira F, Tsoukalas N, Konstantopoulou I, Georgoulias V, Christophyllakis C, Yannoukakos D: A Paternally Inherited BRCA1 Mutation Associated with an Unusual Aggressive Clinical Phenotype. Case Rep Genet. 2014;2014:875029.

26. Konstantopoulou I, Tsitlaidou M, Fostira F, Pertesi M, Stavropoulou AV, Triantafyllidou O, Tsotra E, Tsiftsoglou AP, Tsionou C, Droufakou S et al: High prevalence of BRCA1 founder mutations in Greek breast/ovarian families. Clin Genet. 2014;85(1):36-42.

27. NCCN.org. Genetic/Familial High Risk Assessment: Breast and Ovarian. NCCN Guidelines. 2014;Version 1.2014:1-74.

\section{Submit your next manuscript to BioMed Central and take full advantage of:}

- Convenient online submission

- Thorough peer review

- No space constraints or color figure charges

- Immediate publication on acceptance

- Inclusion in PubMed, CAS, Scopus and Google Scholar

- Research which is freely available for redistribution 